\title{
The emergence of extensively drug-resistant tuberculosis (TB): TB/HIV coinfection, multidrug-resistant TB and the resulting public health threat from extensively drug-resistant TB, globally and in Canada
}

\author{
Paul E Alexander MHSc ${ }^{1}$, Prithwish De MHSc PhD candidate ${ }^{2}$
}

\begin{abstract}
PE Alexander, P De. The emergence of extensively drug-resistant tuberculosis (TB): TB/HIV coinfection, multidrug-resistant TB and the resulting public health threat from extensively drugresistant TB, globally and in Canada. Can J Infect Dis Med Microbiol 2007;18(5):289-291.
\end{abstract}

Resistance to anti-tuberculosis (TB) drugs continues to present a major challenge to global public health. Resistance usually develops due to inadequate TB management, including improper use of medications, improper treatment regimens and failure to complete the treatment course. This may be due to an erratic supply or a lack of access to treatment, as well as to patient noncompliance. However, the emergence and transmission of drug-resistant TB, including the recently detected extensively drug resistant TB (XDR-TB), is driven, in part, by the synergistic relationship between TB and HIV (TB/HIV coinfection). There is evidence that persons infected with HIV are more likely to experience XDR-TB. XDR-TB is virtually untreatable with available TB medications. XDR-TB presents a grave global public health threat, particularly in high HIV prevalence settings. The present commentary discusses the current status of XDR-TB and draws attention to the urgency in addressing this problem, for both the global and Canadian public health networks. XDR-TB and the apparent XDR-TB and HIV association warrants further study.

Key Words: Coinfection; Drug resistance; HIV; MDR-TB; TB/HIV; Tuberculosis; XDR-TB

\section{TUBERCULOSIS AND HIV}

Globally, there are an estimated eight to nine million incident cases of tuberculosis (TB) annually. Approximately $40 \%$ are smear positive (1). Almost one-third of the world's population (approximately two billion), who are mainly living in developing nations, are infected with TB (Mycobacterium tuberculosis infection) (1). Sub-Saharan Africa continues to report the highest burden of HIV (2-4) and accounts for approximately $70 \%$ to $90 \%$ of the estimated 40 million persons infected with HIV (2-4). This African region represents over $70 \%$ of global AIDS mortality, with females bearing a higher AIDS burden (2). Together with Southeast Asia, south Asia and the western Pacific region, it also has the highest prevalence of TB infection and active TB disease (1). Since the mid-1980s, sub-Saharan
L'émergence d'une tuberculose (TB) ultrarésistante aux médicaments : La co-infection par la TB et le VIH, la TB multirésistante aux médicaments et la menace de la TB ultrarésistante aux médicaments pour la santé publique, sur la scène mondiale et au Canada

\begin{abstract}
La résistance aux médicaments contre la tuberculose (TB) continue de poser un grave problème pour la santé publique mondiale. D'ordinaire, la résistance se manifeste en raison d'une prise en charge inadéquate de la TB, y compris un usage incorrect des médicaments, une posologie incorrecte et le fait de ne pas terminer le traitement. Ce phénomène peut s'expliquer par un approvisionnement erratique ou par le manque d'accès au traitement, de même que par la non-adhésion au traitement par le patient. Cependant, l'émergence et la transmission de la TB résistante aux médicaments, y compris la TB ultrarésistante aux médicaments (TB-URM), récemment découverte, sont partiellement imputables à la relation synergique entre la TB et le VIH (la co-infection par la TB et le VIH). Selon des données probantes, les personnes infectées par le VIH risquent davantage de souffrir de TB-URM. La TB-URM est pratiquement impossible à traiter à l'aide des médicaments disponibles. Elle pose une grave menace pour la santé publique sur la scène mondiale, notamment dans les milieux où la prévalence de VIH est élevée. Le présent commentaire traite du statut actuel de la TB-URM et souligne l'urgence de se pencher sur la question, pour les réseaux de santé publique autant mondiaux que canadiens.
\end{abstract}

Africa has experienced an upsurge in TB. This escalation of incident disease has been attributed to HIV, given the previous years of stable TB rates within the region $(1,5,6)$.

$\mathrm{HIV}$ is emerging as a major impediment to TB control and is becoming a major focus of TB prevention efforts, especially for less developed nations. HIV and TB have overlapping epidemiologies. TB is the most common infection reported in persons with HIV. Coinfection with TB and HIV presents challenges beyond treating the individual infection. HIV infection with primary TB leads to more severe infection and promotes reactivation of latent TB. Active TB disease is linked to increments in HIV viral load, locally and systemically, thus, potentially facilitating AIDS sequelae and mortality $(7,8)$. The prevalence of HIV infection in new adult cases of TB was $11 \%$

\footnotetext{
${ }^{1}$ The South Asian Association for Regional Cooperation - Canada (project funded by the Canadian International Development Agency), Health

Canada, Toronto, Ontario; ${ }^{2}$ Department of Epidemiology and Biostatistics, McGill University, Montreal, Quebec

Correspondence: Mr Paul E Alexander, 890 Sheppard Avenue West, U-504, Toronto, Ontario M3H 6B9. Telephone 647-882-4713,

fax 416-634-0027, e-mail elias98_99@yahoo.com

Received and accepted for publication June 28, 2007
} 
in 2000 (1). Approximately $9 \%$ of adult cases were attributable to HIV infection $(1,4)$. Of the nearly two million estimated deaths from TB in 2000, 12\% were attributed to HIV and an estimated $11 \%$ of all adult AIDS deaths were caused by TB (1). Thus, TB reshapes HIV epidemiology globally because it is the major contributor to morbidity and mortality in persons infected with HIV $(1,5,6,9-11)$.

\section{Multidrug-resistant TB}

One consequence of the HIV and TB coepidemics is the increasing occurrence of drug-resistant TB. Resistance to TB therapies can result from improper or incomplete treatment, as well as from patient noncompliance with treatment $(12,13)$. Drug resistance to available TB therapies makes the treatment of TB difficult and expensive; toxic drugs may be required whose effectiveness may be uncertain. Multidrug-resistant TB (MDR-TB) is defined as resistance to at least isoniazid (INH) and rifampicin (14); globally, it has been recognized as a threat to TB control for many years. MDR-TB emerged and became widespread, in part, because of HIV coinfection $(15,16)$. HIV coinfection promotes MDR-TB $(12,13,17,18)$ not only in less developed regions - MDR-TB outbreaks in the United States documented that MDR-TB is highly contagious, often nosocomially acquired within closed settings such as prisons, shelters and hospitals and, for many cases, associated with HIV infection. Such highly drug-resistant institutional-type outbreaks typically result in death unless they are quickly and correctly treated. While antiretroviral treatment for HIV has aided in decreasing mortality in TB/HIV coinfected persons, drug-resistant $\mathrm{TB}$ and MDR-TB strains have increased the mortality in those who are coinfected. This threatens the success of antiretroviral therapy programs for HIV infection, as well as TB control programs.

\section{Extensively drug-resistant TB}

A more recent and alarming global public health threat has emerged with the identification of extensively drug-resistant tuberculosis (XDR-TB) - a highly pathogenic strain of TB developing from MDR-TB (17-23). The present laboratory case definition of XDR-TB (approved by the World Health Organization [WHO] Global Task Force on XDR-TB in 2006) is given as TB resistant to at least rifampicin and INH (consistent with the case definition for MDR-TB) $(14,19)$, in addition to any fluoroquinolone and at least one of three injectable medications (capreomycin, kanamycin and amikacin) used in TB treatment. Furthermore, the WHO defines XDR-TB as MDR-TB that is resistant to three or more of the six classes of second-line drugs $(19,20)$. HIV infection appears to be the impetus for the emergence of this highly virulent strain.

The epidemiological characterization of XDR-TB's distribution remains limited due to the relatively recent recognition of the problem. Nations presently impacted by XDR-TB include Peru, the Philippines, South Africa, Swaziland, Lesotho, Estonia, Latvia, United States, South Korea and Iran $(17,19,21)$. However, the WHO and the Centers for Disease Control and Prevention suggest that the virtually untreatable XDR-TB may exist in all nations (20). Of 17,690 global TB isolates identified between 2000 and 2004, 20\% were MDR-TB and $2 \%$ were XDR-TB. Fifteen per cent of MDR-TB strains in South Korea were identified as XDR-TB in 2004, and 19\% in Latvia between 2000 and 2004 (20,21). This review also reported that for the study period, $4 \%$ of MDR-TB cases in the
United States were classified as XDR-TB (20,21). An Iranian study (17) reported that $8.8 \%$ of 1284 isolates were MDR-TB and, of those, 12 isolates $(10.6 \%)$ in a single-family closecontact cluster showed resistance to all eight second-line medications, and were thus classified as XDR-TB. In a South African study (18), $14.4 \%$ of 1539 isolates were MDR-TB and 53 were XDR-TB. In that study, all XDR-TB patients tested were HIV positive, $85 \%$ of XDR-TB strains were similar and 98.1\% of XDR-TB patients died, even with access to antiretroviral medications $(18,20)$. The median survival period from XDR-TB diagnosis was only 16 days.

These initial reports confirm XDR-TB's contagiousness, ease of spreading among populations coinfected with HIV and rapid mortality, if left untreated. The presence of XDR-TB in populations with HIV is particularly concerning. While the current knowledge is sufficient to identify the issue as one of significant global public health concern, still XDR-TB is an emerging phenomenon.

\section{Is XDR-TB a public health concern for Canada?}

XDR-TB must be regarded as a health concern here in Canada. Even if one infectious patient with XDR-TB was identified in Canada, the high lethality, lack of treatment options and transmissibility would constitute a public health emergency. Epidemiological data suggest that most resistant strains of TB detected in Canada originate from foreign-born patients (14). This knowledge, together with the unique concerns of TB/HIV coinfection as a promoter of XDR-TB, needs to be considered in developing strategies to address this problem in Canada.

\section{FUTURE CONSIDERATIONS}

The immediate public health significance of XDR-TB must be recognized, and programs should be developed to address the challenge, both globally and within Canada. There is an urgent need to characterize the extent and geographical distribution of XDR-TB. Sex-stratified data are essential, as well as characterization of differences in clinical features, if any, among men and women. Characterization of the extent of both MDR-TB and XDR-TB among children is needed, as well as among vulnerable and marginalized high-risk subpopulations, such as the Native population within Canada. Studies characterizing the genetics, biochemistry and molecular characteristics of XDR-TB infection in persons both with and without HIV infection are also essential.

Increased TB and HIV program collaboration should be considered. In light of the severity of XDR-TB based on emerging evidence, existing TB control programs should be realigned toward strategies that enhance TB and HIV prevention, detection and control, nationally and globally. TB control programs should incorporate HIV testing and counselling services if they are not already doing this. Increased testing and treatment for TB in HIV testing centres and infected patients should also be promoted. Intensified efforts for active TB case findings, particularly in HIV-infected persons, should be pursued. The detection and control of HIV-linked TB, especially in regions of elevated HIV prevalence, are paramount. Urgent intervention must be accompanied by testing for XDR-TB, especially in developing nations with elevated TB, HIV and TB/HIV coinfection rates. Screening and testing with treatment for sexually transmitted diseases among TB patients may also mitigate the risk for HIV, with the potential for reducing 
the sexually transmitted disease, HIV, active TB disease, MDR-TB and XDR-TB sequelae.

The emergence of MDR-TB and XDR-TB highlights the need for cheaper, safer and more effective anti-TB second-line treatments. Intensified and expanded directly observed therapy short-course TB treatment programs, especially in high HIVprevalent populations, may limit the spread of XDR-TB. Increased TB case findings and detection, as well as testing of HIV-positive persons for TB infection and subsequent INH preventive therapy to prevent disease sequelae are also necessary. Challenges in the concurrent treatment of TB and HIV include drug toxicity. There is also a need for quality-assured laboratory testing, including rapid diagnostic testing, to minimize the transmission of drug-resistant TB. Laboratory surveillance for MDR-TB must include XDR-TB.

Canadian prevention and control programs can address the emerging XDR-TB threat by refining existing TB control programs to include XDR-TB (eg, in patient management). This can include second-line drug susceptibility testing, adoption of the WHO's case definition, availability of rapid diagnostic testing and training for diagnosticians to recognize cases, enhanced infection control strategies, enhanced acute surveillance to monitor XDR-TB, and increased collaborations and communications on XDR-TB within public health systems.

\section{REFERENCES}

1. Corbett EL, Watt CJ, Walker N, et al. The growing burden of tuberculosis: Global trends and interactions with the HIV epidemic. Arch Intern Med 2003;163:1009-21.

2. UNAIDS. UNAIDS/WHO "AIDS epidemic update: December 2006". <http://www.unaids.org/en/HIV_data/epi2006/default.asp> (Version current at July 26, 2007).

3. UNAIDS/WHO. AIDS epidemic update, December 2002. $<$ http://data.unaids.org/Publications/IRC-pub03/ epiupdate2002_en.pdf $>$ (Version current at July 26, 2007).

4. World Health Organization, AIDS Epidemic update: December 2003. <http://www.who.int/hiv/pub/epidemiology/ epi2003/en/index.html > (Version current at July 26, 2007).

5. Raviglione MC, Harries AD, Msiska R, Wilkinson D, Nunn P. Tuberculosis and HIV: Current status in Africa. AIDS 1997;11(Suppl B):S115-23.

6. Cantwell MF, Binkin NJ. Impact of HIV on tuberculosis in sub-Saharan Africa: A regional perspective. Int J Tuberc Lung Dis 1997;1:205-14.

7. Goletti D, Weissman D, Jackson RW, et al. Effect of Mycobacterium tuberculosis on HIV replication. Role of immune activation. J Immunol 1996;157:1271-8.

8. Toossi Z. Virological and immunological impact of tuberculosis on human immunodeficiency virus type 1 disease. J Infect Dis 2003;188:1146-55.

9. JP Narain, ed. Tuberculosis: Epidemiology and Control, 2002. New Delhi: World Health Organization Regional Office for SouthEast Asia, 2002.

10. Cosivi O, Grange JM, Daborn CJ, et al. Zoonotic tuberculosis due to Mycobacterium bovis in developing countries. Emerg Infect Dis 1998;4:59-70.

11. Zachariah R, Teck R, Ascurra O, et al. Can we get more HIVpositive tuberculosis patients on antiretroviral treatment in a rural district of Malawi? Int J Tuberc Lung Dis 2005;9:238-47.

12. Frieden TR, Sherman LF, Maw KL, et al. A multi-institutional outbreak of highly drug-resistant tuberculosis: Epidemiology and clinical outcomes. JAMA 1996;276:1229-35.
Mandatory reporting of XDR-TB cases to local, provincial or federal health ministries, and increased funding for antimicrobial (anti-TB) drug research in Canada, must also be addressed.

\section{CONCLUSION}

XDR-TB is a global public health threat because it is virtually untreatable. It is currently more prevalent than global, regional, national or local public health systems have recognized, and there is no room for complacency. Urgent action is needed to prevent XDR-TB from further dissemination. Global public health is now confronting a form of TB that responds poorly to available treatments and prevention efforts. The emergence of XDR-TB has the potential to reverse the gains made by TB and HIV control programs, with major implications for developing nations that have high rates of both TB and HIV infection (18). It may also be relevant to at-risk persons living in congregated settings, institutions or rural communities where prevention and treatment services may be limited. Left unchecked, global HIV and TB epidemiology will be reshaped by MDR-TB and XDR-TB, and by their intersection with the continuing HIV epidemic. Fortunately, HIV infection is preventable, and drug-susceptible TB is curable. We need to rapidly and fully implement strategies to address this new challenge.

13. Beck-Sagué C, Dooley SW, Hutton MD, et al. Hospital outbreak of multidrug-resistant Mycobacterium tuberculosis infections. Factors in transmission to staff and HIV-infected patients. JAMA 1992;268:1280-6.

14. Yang H, Field SK, Fisher DA, Cowie RL. Tuberculosis in Calgary, Canada, 1995-2002: Site of disease and drug susceptibility. Int J Tuberc Lung Dis 2005;9:288-93.

15. Campos PE, Suarez PG, Sanchez J, et al. Multidrug-resistant Mycobacterium tuberculosis in HIV-infected persons, Peru. Emerg Infect Dis 2003;9:1571-8.

16. Punnotok J, Shaffer N, Naiwatanakul T, et al. Human immuno-deficiency virus-related tuberculosis and primary drug resistance in Bangkok, Thailand. Int J Tuberc Lung Dis 2000;4:537-43.

17. Masjedi MR, Farnia P, Sorooch S, et al. Extensively drug-resistant tuberculosis: 2 years of surveillance in Iran. Clin Infect Dis 2006; $43: 841-7$.

18. Gandhi NR, Moll A, Sturm AW, et al. Extensively drug-resistant tuberculosis as a cause of death in patients co-infected with tuberculosis and HIV in a rural area of South Africa. Lancet 2006;368:1575-80.

19. World Health Organization - tuberculosis (TB). XDR-TB extensively drug-resistant tuberculosis. <http://www.who.int/tb/ $\mathrm{xdr} / \mathrm{en} /$ index.html $>$ (Version current at July 26, 2007).

20. World Health Organization. Emergence of XDR-TB: WHO concern over extensive drug resistant TB strains that are virtually untreatable. <http://www.who.int/mediacentre/news/notes/2006/ np23/en/index.html > (Version current at July 26, 2007).

21. Centers for Disease Control and Prevention (CDC). Emergence of Mycobacterium tuberculosis with extensive resistance to second-line drugs - worldwide, 2000-2004. MMWR Morb Mortal Wkly Rep 2006;55:301-5.

22. Dahle UR. Extensively drug resistant tuberculosis: Beware patients lost to follow-up. BMJ 2006;333:705.

23. Raviglione MC, Smith IM. XDR tuberculosis - implications for global public health. N Engl J Med 2007;356:656-9. 


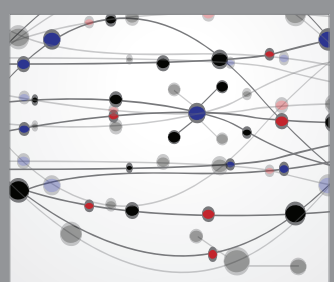

The Scientific World Journal
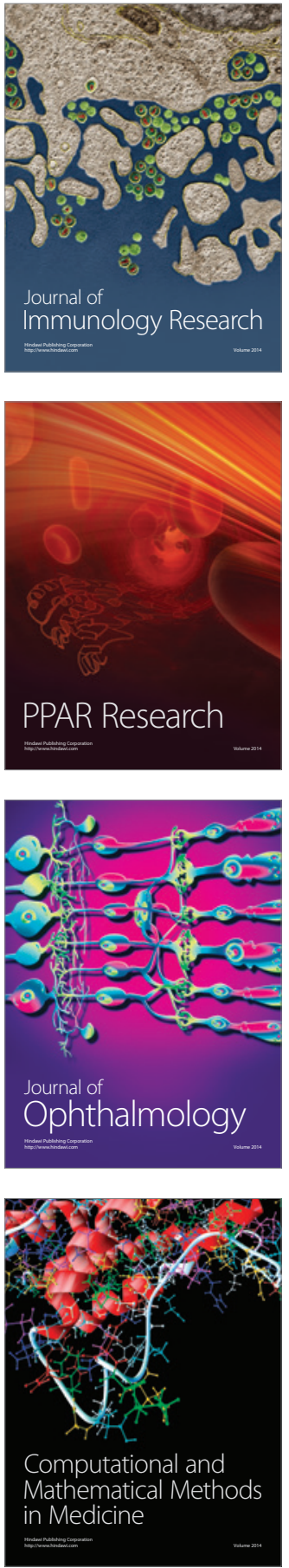

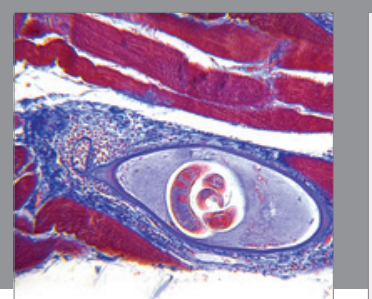

Gastroenterology Research and Practice

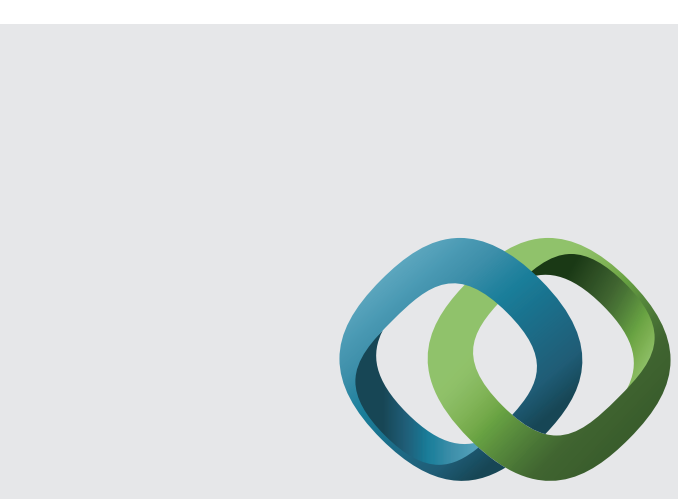

\section{Hindawi}

Submit your manuscripts at

http://www.hindawi.com
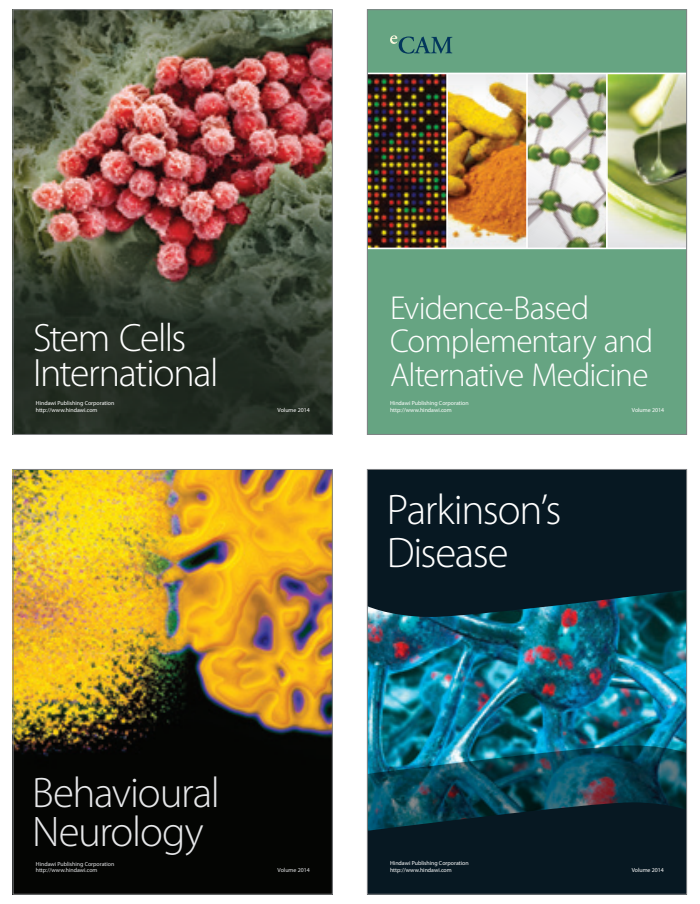
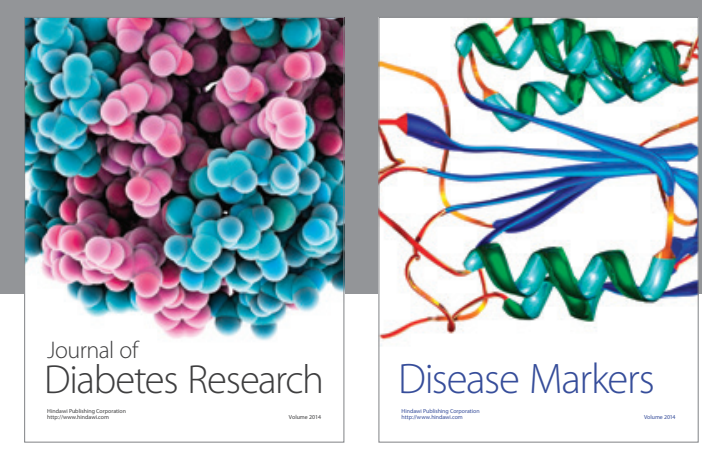

Disease Markers
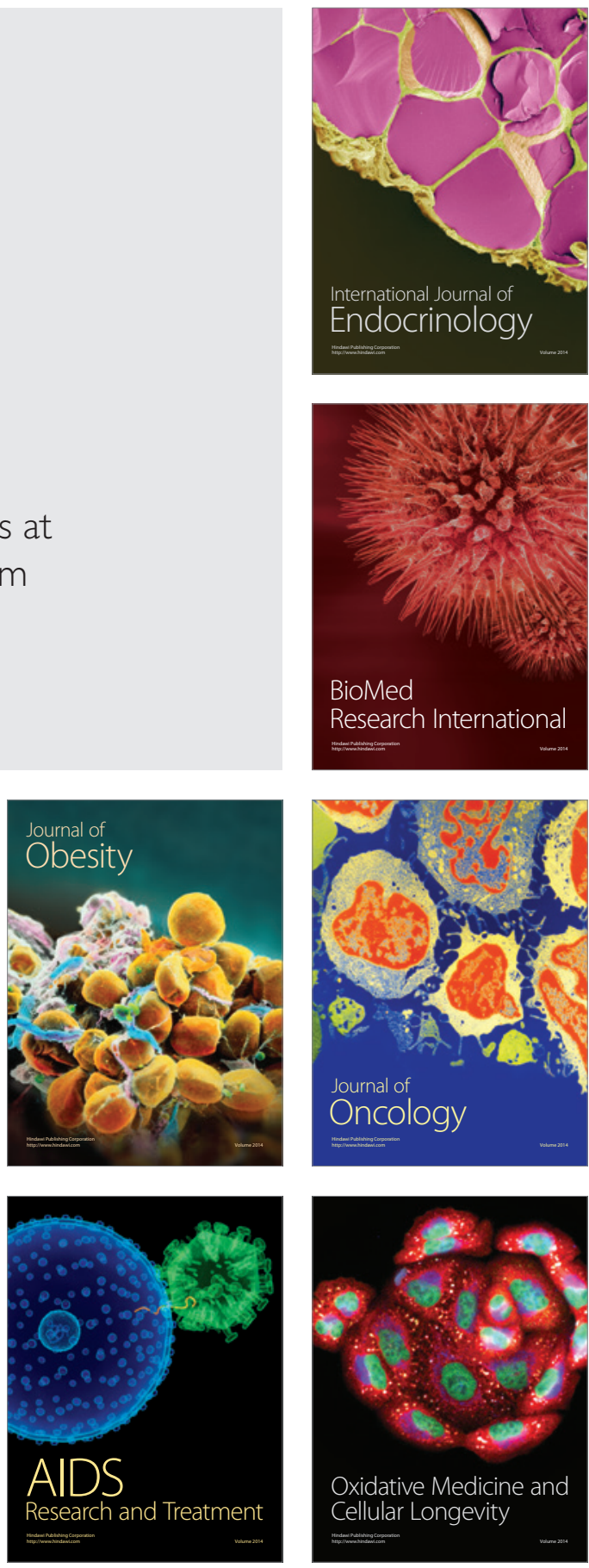